\& J. Edu. \& Sci., Vol. (24), No. (3) 2011 \&

\title{
Laser Field Distribution in Photonic Crystal Fiber With Triple Zero Dispersion Wavelengths
}

\author{
Abdulghafoor Ibrahim Abdullah \\ Department of Physics / College of Education \\ University of Mosul \\ Received \\ 23 / 02 / 2010 \\ Accepted \\ 21 / 07 / 2010
}

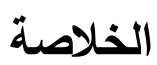

الهدف من هذ ا البحث هو دراسة خصائص ألألياف البلورية الفوتونية و توزيع مجال ضوء الهو

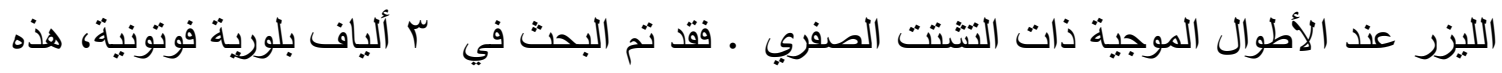
الألياف تتميز بوجود فجوة هوائية واحدة مفقودة في المركز و وجود الحلقة الأولى فقط من الفجوات الهوائية (7 فجوات هوائية) حول القلب.

في الليف الأول، المسافة بين مركزي اي فجوتين متجاورتين وقطر الفجوة

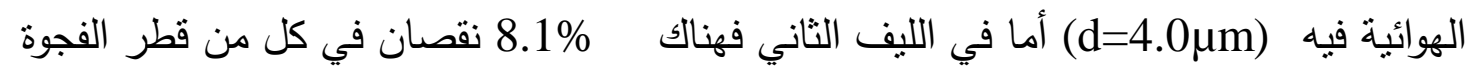
الهوائية (d) والمسافة بين مركزي اي فجوتين متجاورتين (ب). لكن في الليف الثالث كان النقصان

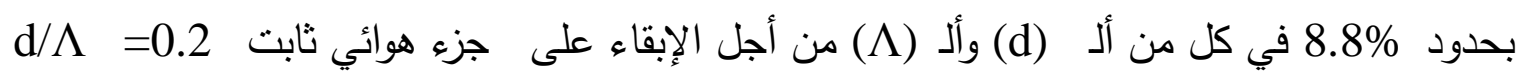
للنماذج المقترحة من الألياف التي تعمل بالنمط المنفرد. خصائص التراكيب المقترحة والتي تشمل الجزي التئ الحقيقي والجزء الخيالي لمعامل الانكسار

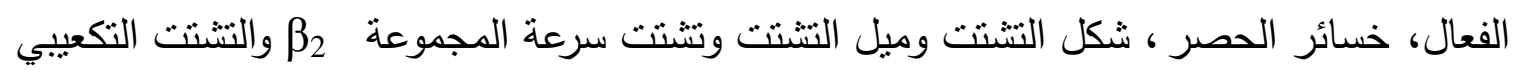

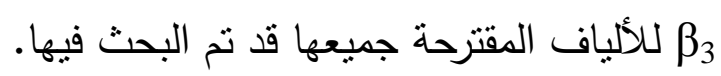

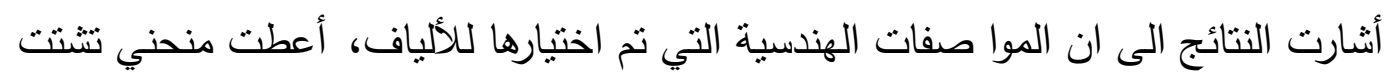

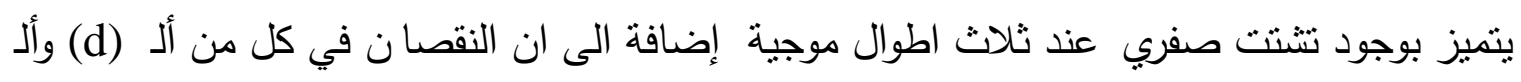

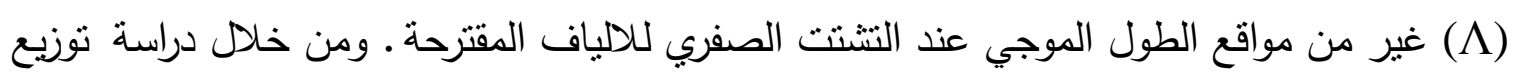
مجال ضوء الليزر في الالياف البلورية الفوتونية، تبين ان جميع التصاميم المقترحة تعمل بنمط منفرد عند نوافذ الاتصالات الضوئية في حين خسائر الحصر زادت عند الأطوال الموجية الأطول.

\section{Abstract}


The aim of this work is to study the properties of the photonic crystal fibers (PCFs) and the laser field distribution at the zero dispersion wavelengths (ZDWs).

Three PCFs are proposed, all the PCFs have one missing hole and one ring of holes around the core ( 6 holes). For PCF1, the hole diameter $\mathrm{d}=4.0 \mu \mathrm{m}$ and the pitch size $\Lambda=2.0 \mu \mathrm{m}$. In PCF2 a $8.1 \%$ reduction in both $\mathrm{d}$ and $\Lambda$. While $8.8 \%$ reduction in $\mathrm{d} \& \Lambda$ for the PCF3 in order to keep the air filling fraction $(\mathrm{AFF})(\mathrm{d} / \Lambda=0.2)$ constant for structures which are operating in single mode regime.

The real and the imaginary parts of the effective refractive index, confinement loss, dispersion profile, dispersion slope, group velocity dispersion $\beta_{2}$ and cubic dispersion $\beta_{3}$ all are investigated.

The results show that the proposed structures gives dispersion profile with triple zero dispersion wavelength, and the reduction in $\mathrm{d}$ and $\Lambda$ changes the positions of the triple ZDWs.

The results of the laser field distribution in the PCFs show that all the structures are working in the single mode, while for the PCF3, the field are slightly extended toward the clad region at longer wavelength.

\section{Introduction}

Recently, rapid progress has been made in photonic crystal fibers PCFs. There are two basic types of photonic crystal fibers, namely, hollow core photonic crystal fiber HC-PCFs and solid core photonic crystal fiber SC- PCFs. Generally in PCFs, six air holes are arranged on the first ring in hexagonal symmetry which is known as the hexagonal PCFs (H-PCFs)[1,2]. The cladding structure is formed by a periodic hexagonal pattern of air-holes around the central core. The air-holes lower the effective refractive index of the cladding. Hence, light is guided within the PCF by total internal reflection TIR, this type is also called an index guiding PCF. While for HCPCFs, because its core index (air) is lower than the effective index of the cladding (periodic array of air holes), guidance via TIR is impossible, so the only possible guidance mechanism is photonic band gap (PBG) effect [2]. By this effect the light is guided in a low index region.

PCFs have some unique properties that cannot be achieved from conventional step index fiber SIF such as endlessly single mode, flattened dispersion [3], dispersion profile with one zero dispersion wavelengths [4,5] or double ZDWs [6].

The properties mentioned above can be controlled either by manipulating the main parameters of the PCFs, such as hole diameter $\boldsymbol{d}$, inter hole spacing (or pitch size) $\boldsymbol{\Lambda}$, number of hole rings $\mathbf{N r}$ and number of 
missing holes $\boldsymbol{M N r}$ (which are illustrated in Fig.1), or by varying only the doping concentration of the silica rods (instead of air rod). The doping technique used by Gowre et al [7] shifted the ZDW to low loss window. On the other hand, multiple ZDWs is obtained by Agrawal et al [8] when the holes arranged in spiral manner in the cladding of the PCFs.

All these properties of the PCFs make them useful candidate for dense wavelength division multiplexing DWDM, supercontinuum generation SCG, and dispersion compensation application [9].

The research of PCFs have been subject of many groups; Knight et al [10] Kuhlmy et al [11] Ferrando et al [12], and have modeled solid core PCF by different numerical tools [9,11], empirical relations [13], or used $\boldsymbol{C U D O S}$ MOF software [11] for determining the waveguide parameters for light propagation in photonic crystal fiber.

In this paper $\boldsymbol{C U D O S}$ software based on Multipole method is used for controlling the dispersion profile, and obtaining triple ZDWs with less number of control parameters. The manipulation will be only with the hole diameter $\boldsymbol{d}$ and inter hole space $\boldsymbol{\Lambda}$ while the number of the missing hole, number of air hole rings and air filling fraction $\boldsymbol{A F F}$ of the proposed structures all are kept constant.

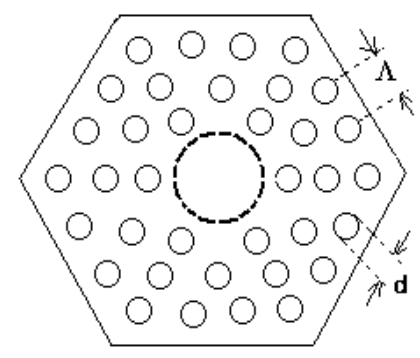

Fig. 1: Schematic drawing of a PCF, represents air hole diameter $d$ and the inter hole spacing $\Lambda, N r=3, M N r=1$

\section{Descriptions of The PCFs Geometry and Used Software}

The structures consisting of a pure silica with refractive index 1.4632264867 at $\lambda=0.5 \mu \mathrm{m}$ are considered. For The PCF1 the air holes of diameter $(\boldsymbol{d}=0.4 \mu \mathrm{m})$ are arranged on a hexagonal form with inter hole spacing $(\Lambda=2.0 \mu \mathrm{m})$. In the center of all the proposed structures are one air hole is missed $(\boldsymbol{M N r}=1)$ creating a central high index defect serving as the core of the fiber. The number of the hole rings is $(\mathbf{N r}=1)$ the first air holes ring around the core is consist of 6 holes, means the number of the air holes in this structure is $(\boldsymbol{N H}=6)$ only. For PCF2 and PCF3 same values of $\boldsymbol{M N r}$, $\boldsymbol{N r}, \boldsymbol{N H}$, and $\boldsymbol{A F F}$ as in PCF1 but $\boldsymbol{d}$ and $\boldsymbol{\Lambda}$ are reduced $8.1 \%$ for PCF2 (i.e 
$\boldsymbol{d}=0.367 \mu \mathrm{m}$ and $\boldsymbol{\Lambda}=1.838 \mu \mathrm{m}$ ) and $8.8 \%$ for PCF3 (i.e $\boldsymbol{d}=0.334 \mu \mathrm{m}$ and $\Lambda=1.676 \mu \mathrm{m})$

Accordingly, the core radius $\boldsymbol{R}_{\boldsymbol{c}}$ of the PCFs mentioned above are not the same and calculated by the following relation:

$$
R_{c}=\operatorname{Nr} \times \boldsymbol{\Lambda}-d / 21
$$

The schematic illustration of the proposed PCFs structure is shown in Fig.2. Depending on the dimension of the proposed structures, Air Filling Fraction $\boldsymbol{A F F}=\left(\boldsymbol{\pi} / 2^{\sqrt{ } 3}\right)(\boldsymbol{d} / \boldsymbol{\Lambda})^{2}$ [14] for the triangular lattice PCFs or the relative air hole size is $\boldsymbol{d} / \boldsymbol{\Lambda}<0.4$ for the proposed PCFs, that means the parameters of the structures, at the beginning, are located in endlessly single mode region as shown in Fig .3.

To calculate the real part of the effective refractive index $R\left(n_{\text {eff }}\right)$ and the imaginary part of the effective refractive index $\operatorname{Im}\left(\mathrm{n}_{\text {eff }}\right)$ the software $\boldsymbol{C U D O S}$ is used [15]. The $\boldsymbol{C U D O S}$ (Center for Ultra Bandwidth Devices for $\boldsymbol{O}$ ptics $\boldsymbol{S}$ ystems) program is an implementation of the multipole method which is written by Kuhlmey[16]. The precision of the calculated mode indices have been found by an amount $1 \times 10^{-11}$ for the real part and for an imaginary part of the index is found by $1 \times 10^{-15}$ [16]. The properties of the PCFs presented in this paper are calculated by programs written by the author of this paper.

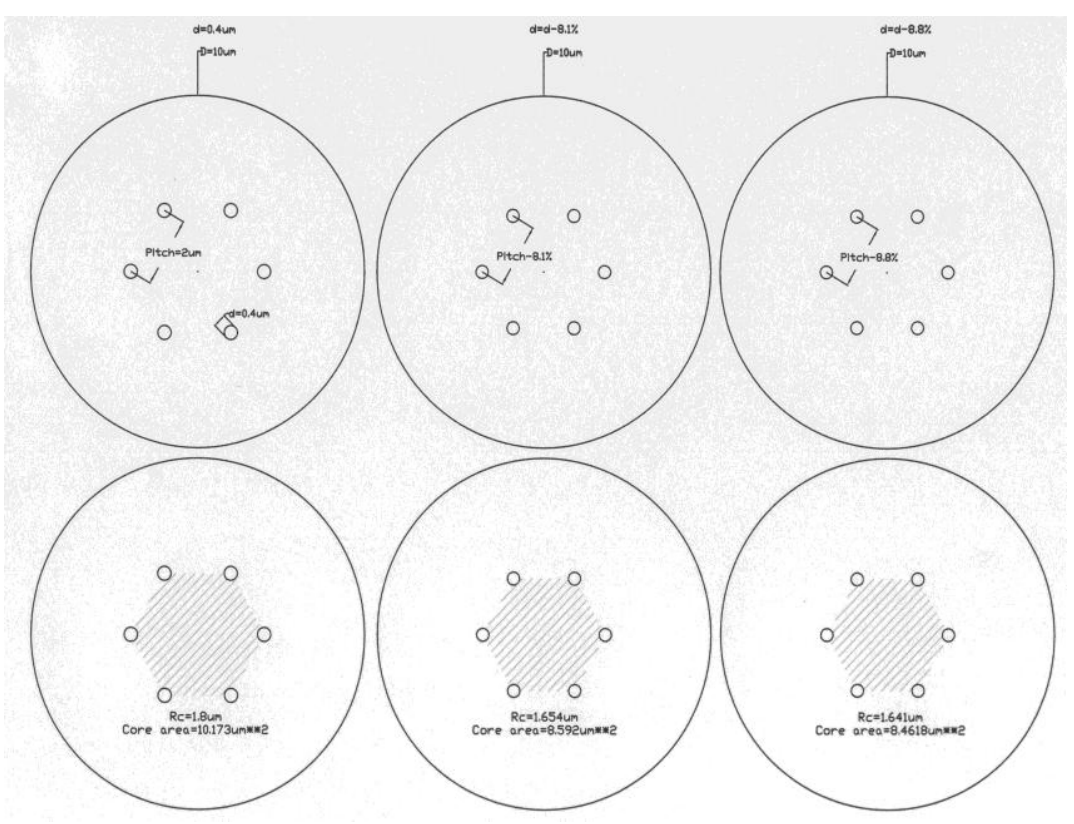

Fig.2. Schematic illustration of the cross section of the proposed structures with core radius $R_{c}=N r \times \Lambda-d / 2$, The top three structures show the geometric parameters of the structures. The bottom three structures show the calculated core area of the structures. 


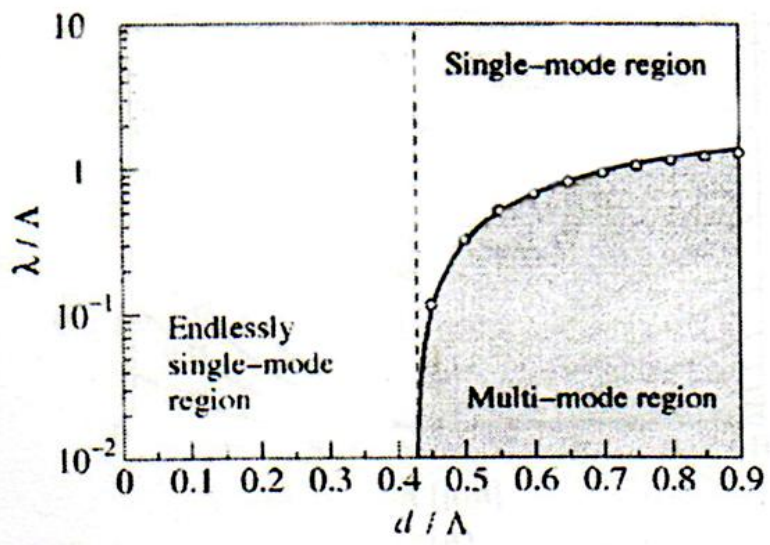

Fig.3. Diagram illustrating phases with single mode and multi mode operation[17]

\section{Some Concepts and Theoretical Relations Used in This Study \\ 3.1 Material Dispersion}

Material dispersion occurs in optical fiber because the refractive index $n(\lambda)$ of silica is a function of the wavelength $\lambda[18]$. The origin of material dispersion is related to the characteristic resonance frequencies at which the medium absorbs the electromagnetic radiation through oscillations of bound electrons. The refractive index dependence on wavelength is approximated by Sellmeier equation[19]:

$$
n^{2}(\lambda)=1+\sum_{i=1}^{s} \frac{A_{i} \lambda^{z}}{\lambda^{z}-\lambda_{i}^{z}}
$$

where $A_{i(1,2,3)}$ and $\lambda_{i(1,2,3)}$ are coefficients related to material oscillator strength and oscillator wavelengths respectively. The values of these coefficients, for bulk silica, are obtained empirically by Sellmeier equation, and these values are [19]:

$$
A_{1}=0.9691663, A_{2}=0.4079426 \text {, and } A_{3}=0.8974794
$$

$\lambda_{1}=0.0680430, \lambda_{2}=0.1162414$, and $\lambda_{3}=9.8961610$

\subsection{Quadratic Dispersion $\beta_{2}$ and Cubic Dispersion $\beta_{3}$}

The effects of fiber dispersion can be understood by expanding the mode propagation constant $\beta(\omega)$ in a Taylor series about the frequency $\omega_{0}$ at which the pulse spectrum is centered [20,21]:

$\beta(\omega)=\beta\left(\omega_{0}\right)+\left(\omega-\omega_{0}\right) \beta_{1}+\left(\frac{1}{2 !}\right)\left(\omega-\omega_{0}\right)^{2} \beta_{2}+\left(\frac{1}{3 !}\right)\left(\omega-\omega_{0}\right)^{3} \beta_{3}+\ldots \ldots$.

Where $\beta_{m}=\left(\frac{\partial^{\mathrm{m}} \beta}{\partial \omega^{\mathrm{m}}}\right), \mathrm{m}=0,1,2$, 
$\beta_{2}$ : is a parameter which is called quadratic dispersion or group velocity dispersion GVD, and it is responsible for pulse broadening and is expressed in unit of $\left(\mathrm{ps}^{2} / \mathrm{km}\right) . \beta_{2}$ in terms of the effective refractive index can be given by the following relation [21]:

$\beta_{z}=\frac{1}{c}\left(2 \frac{d n_{\text {eff }}}{d \omega}+\omega \frac{d^{2} n_{\text {eff }}}{d \omega^{2}}\right)$

The dispersion parameter $\mathrm{D}(\mathrm{ps} / \mathrm{km} / \mathrm{nm})$ is used to describe the total dispersion of a single mode fiber and is related with the second derivative of the $\left(\mathrm{n}_{\text {eff }}\right)$ with respect to the wavelength and the quadratic dispersion $\beta_{2}$ as the following equations:

$D(\lambda)=-\frac{\lambda d^{2} n_{\text {eff }}}{d \lambda^{2}}$

$D(\lambda)=-\frac{2 \pi c}{\lambda^{2}} \beta_{2}$

The value of the group velocity dispersion $\beta_{2}$ is either positive or negative. Which means in the normal dispersion region $\left(\beta_{2}>0\right)$, longer wavelength pulse travels faster, while in the anomalous dispersion region $\left(\beta_{2}\right.$ $<0)$, shorter wavelength pulse travels faster [20,21].

In many materials, a frequency exists at which the quadratic dispersion $\beta_{2}$ become zero, the corresponding wavelength (known as $\lambda_{\mathrm{ZD}}$ ) is the wavelength at which the dispersion $\mathrm{D}(\lambda)$ is zero. Under this condition cubic dispersion $\beta_{3}\left(\mathrm{ps}^{3} / \mathrm{km}\right)$ will be important and can be expressed in terms of the dispersion $\mathrm{D}(\lambda)$ and its first derivative which is known as dispersion slope $d D(\lambda) / d \lambda\left(\mathrm{ps} / \mathrm{nm}^{2} / \mathrm{km}\right)$ as the following [20]:

$\beta_{a}=\frac{\lambda^{3}}{2 \pi^{2} c^{2}}\left(D(\lambda)+\frac{\lambda}{2} \frac{d D}{d \lambda}\right)$,

It is worth to say that the dispersion slope $d D(\lambda) / d \lambda$ is used as a measure of the flatness of the dispersion profile and can be calculated by the following expression [20].

$$
\frac{d D}{d \lambda}=\frac{-1}{c}\left(\frac{d^{2} n_{e f f}}{d \lambda^{2}}+\lambda \frac{d^{3} n_{e f f}}{d \lambda^{3}}\right)
$$

\section{Results and Discussions}

The relation between the real part of effective refractive index $R\left(\mathrm{n}_{\text {eff }}\right)$ which is obtained from $\boldsymbol{C U D O S}$ MOF software for the proposed PCFs and the refractive index for silica, which is obtained from Sellmeier equation Eq.(2), both are plotted aginst wavelength are illustrated in Fig.(4). 
It is evident from the figure that there is a significant difference in the real part of the effective refractive index for the structures, such difference due to the change in the hole diameter and pitch size. The figure shows that the reduction in both the hole diameter $\boldsymbol{d}$ and the pitch size $\boldsymbol{\Lambda}$ cause a reduction in the effective refractive index for PCF2 and PCF3 in all the considered wavelength range. On the other hand the reduction in both $\boldsymbol{d} \& \boldsymbol{\Lambda}$ cause also more increase in the difference between the refractive index of the silica and the refractive index of the PCF3 for the fundamental mode comparing to the refractive index of both PCF2 and PCF1 respectively.

Fig.4 shows also that the real part of the effective refractive index at shorter wavelength is approaching the core refractive index, while for long wavelength is significantly below the core refractive index for the structures under study.

Fig. 5 shows the relation between the imaginary part of the refractive index $\operatorname{Im}\left(\mathrm{n}_{\text {eff }}\right)$ of the proposed structures as a function of wavelength. We found, for all the PCFs, the imaginary part of the refractive index is increased exponentially with increasing the wavelength. On other hand PCF1 of $\boldsymbol{\Lambda}=2.0 \mu \mathrm{m}$ and $\boldsymbol{d}=0.4 \mu \mathrm{m}$ has lower imaginary part, in all the considered wavelength range, comparing with PCF2 \&PCF3.

As known, confinement loss is a form of losses that occurs in single mode fiber. The properties of the fiber are determined by the geometry of the structures, this structure affects the value of the $\operatorname{Im}\left(\mathrm{n}_{\text {eff }}\right)$. Figure 5 shows the $\operatorname{Im}\left(\mathrm{n}_{\mathrm{eff}}\right)$, which is obtained from for different structures, we can say that the value of $\operatorname{Im}\left(\mathrm{n}_{\text {eff }}\right)$ gives a good indication for the level of confinement losses $(\mathrm{dB} / \mathrm{m})$ by using the following equation [11].

$C L=\frac{40 \pi}{\ln 10 \lambda(\mu m)} \operatorname{Im}\left(n_{\text {eff }}\right) \times 10^{6}$,

By using Eq.(9) and according to Fig.5 the results of $C L$ in unit of $\mathrm{dB} / \mathrm{m}$ are reported in Table (1). When $\boldsymbol{d} \& \boldsymbol{\Lambda}$ are reduced $8.1 \%$ and $8.8 \%$ for PCF2 \& PCF3 respectively, means the core radius of the proposed fiber is reduced also. The reduction in both $\boldsymbol{d} \& \boldsymbol{\Lambda}$ cause an increase in the light leakage to the clad, that means an increase in the confinement losses for PCF2 \& PCF3 along the scale of the wavelength under study. This result agrees well with published work $[13,14]$. The calculated confinement loss for the proposed PCFs are: with $\boldsymbol{d} / \boldsymbol{\Lambda}=0.2$ the $C L$ changes from $18 \times 10^{5} \mathrm{~dB} / \mathrm{m}$ ( at $1.55 \mu \mathrm{m}$ ) for PCF1 to $24 \times 10^{5} \mathrm{~dB} / \mathrm{m}$ for PCF2 and to $33 \times 10^{5} \mathrm{~dB} / \mathrm{m}$ for PCF3 at the same window. $C L$ for the proposed PCFs are listed in Table (1). 


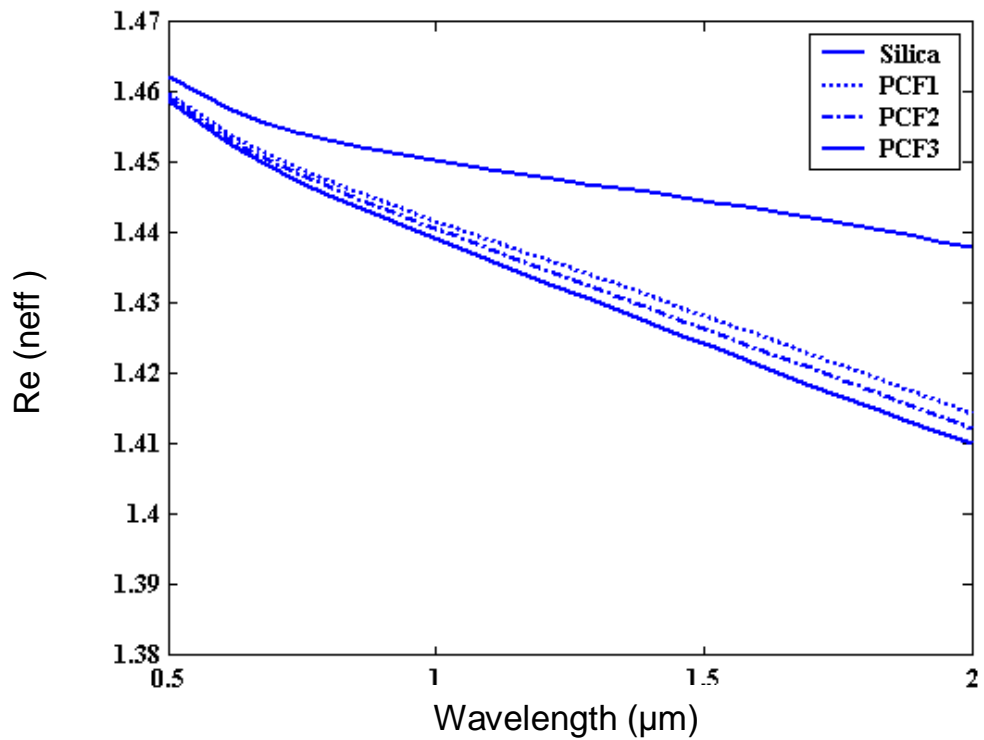

Fig.4. Real part of the refractive index of the fundamental mode as a function of wavelength for the PCFs. The bold line (Top) for silica

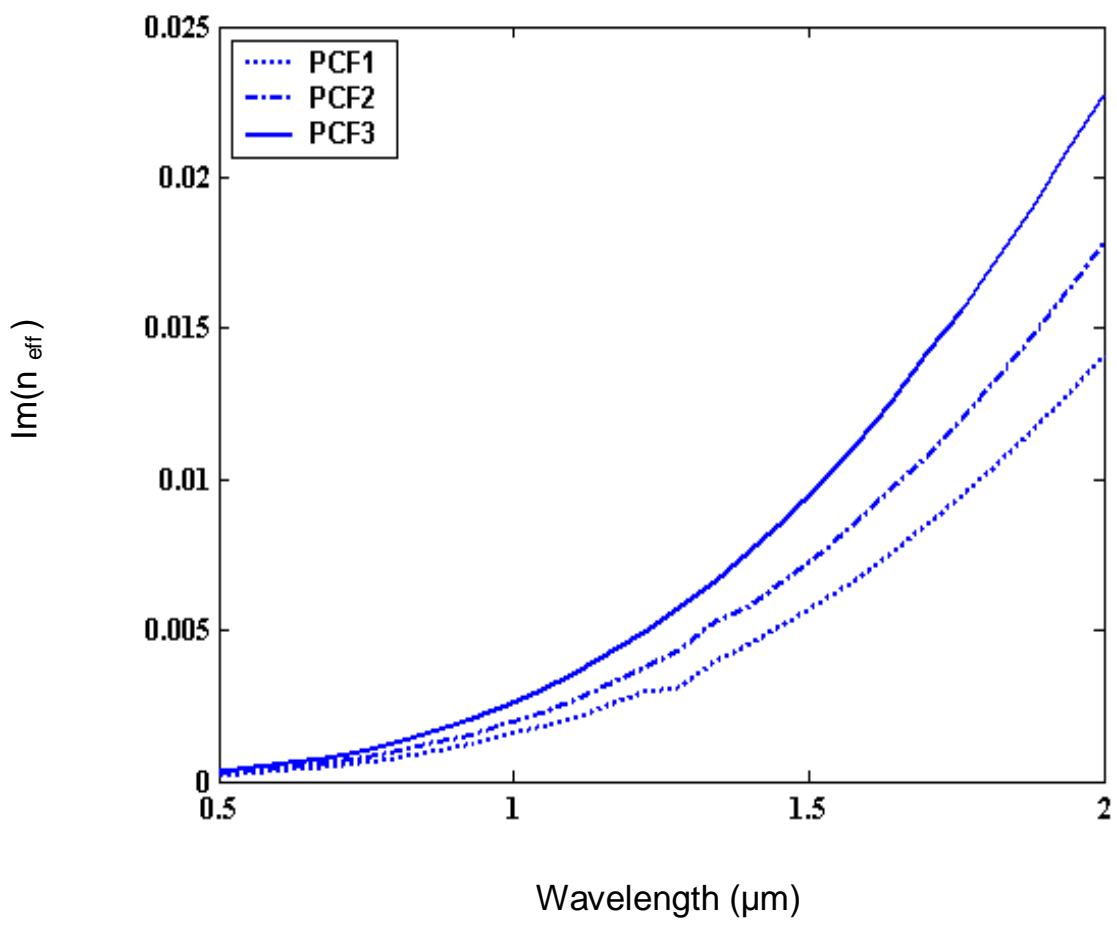

Fig. 5. Imaginary part of the refractive index of the fundamental mode as a function of wavelength for the PCFs. 


\section{Dispersion $\mathrm{D}(\lambda)$ of The Triple ZDWs}

The dispersion as a function of wavelength is plotted in Fig. 6 using Eq. (5). In Fig.6 A, B and $\mathrm{C}$ the dispersion profile is for the structures of same $A F F$ ( i.e $\mathrm{d} / \Lambda=0.2$ ) but the hole diameter $\boldsymbol{d}$ and the pitch size $\Lambda$ of PCF2 are reduced $8.1 \%$ of PCF1and for PCF3 $8.8 \%$ of PCF2, as shown in Fig $\mathrm{B}$ and $\mathrm{C}$ respectively. The results show that for a fixed $A F F$ there are an optimum values of $\boldsymbol{d}$ and $\boldsymbol{\Lambda}$ for achieving triple ZDWs. Otherwise single or double ZDW may exist. Table (1) shows the parameters of the triple ZDWs PCFs under study, such parameters are triple ZDWs, ZDWs separation, dispersion parameter, dispersion slope at communication windows and cubic dispersion. This table shows (according to Fig.(6)) ZDW3 at range $(1.7 \mu \mathrm{m}-$ $1.9 \mu \mathrm{m})$ is red shifted toward the longer wavelength with reduction of the $\boldsymbol{d}$ and $\boldsymbol{\Lambda}, \mathrm{ZDW} 1$ is also red shifted at range $(1.07 \mu \mathrm{m}-1.15 \mu \mathrm{m})$ of wavelength. While ZDW2 is (blue shifted). On the other hand the first two ZDWs separation are reduced and the closest ZDWs are 200nm for PCF3. While the second two ZDWs separation are increased and the maximum separation are 510nm again for PCF3. Furthermore, the table shows also the proposal structures have negative dispersion $\sim 100 \mathrm{ps} / \mathrm{nm} / \mathrm{km}$ at window $0.8 \mu \mathrm{m}$, (the wave length of laser emission of Ti-Za laser) which is important for Dense WDM and dispersion compensation application [22] as mentioned by Saitoh et al (2006). Table (1) shows also that the dispersion slope of triple ZDW PCF can be changed by reduction of $\boldsymbol{d}$ and $\boldsymbol{\Lambda}$. The dispersion slope of PCF1 $\&$ PCF2 at the windows $1.3 \mu \mathrm{m} \& 1.55 \mu \mathrm{m}$ are $0.07 \sim 0.1 \mathrm{ps} / \mathrm{nm}^{2} / \mathrm{km}$ (where the typical value is $0.091 \mathrm{ps} / \mathrm{nm}^{2} / \mathrm{km}$ for the traditional fiber[20]).

The effect of cubic dispersion (when the quadratic dispersion is zero) is important, so that the large value of $\beta_{3}$ make the propagated pulse asymmetric. If the PCFs has negative $\beta_{3}$ the oscillation occur on the pulse leading edge, while for positive $\beta_{3}$, the oscillation occur on the pulse tail. The values of $\beta_{3}$ are listed in Table (1) for the PCFs under study.

\section{Laser Field Distribution of The Fundamental Mode in PCFs With Triple ZDWs}

The laser field distribution of the guided mode in Triple ZDW PCF is shown in Fig.7. The field distribution is illustrated at three communication wavelengths $0.8 \mu \mathrm{m}, 1.3 \mu \mathrm{m}$ and $1.55 \mu \mathrm{m}$. It is clear that the light can be guided in the core with small different profiles depends mainly on the fiber structure and the communication windows.

For PCF 1 of $\mathrm{d} / \Lambda=0.2$, we can see the strong confinement of the laser light in the core of PCF1. The field avoids the holes at Ti-Za laser of $0.8 \mu \mathrm{m}$ compared with the same structure but at longer wavelength $1.55 \mu \mathrm{m}$, i.e the field is slightly extended toward the first ring due to the confinement loss. Furthermore, Fig.7 shows also that the field distribution in proposed 
structures of PCF with triple ZDWs is similar to the fundamental guided mode [23], which means the triple ZDWs PCF is still operated in single mode regime.
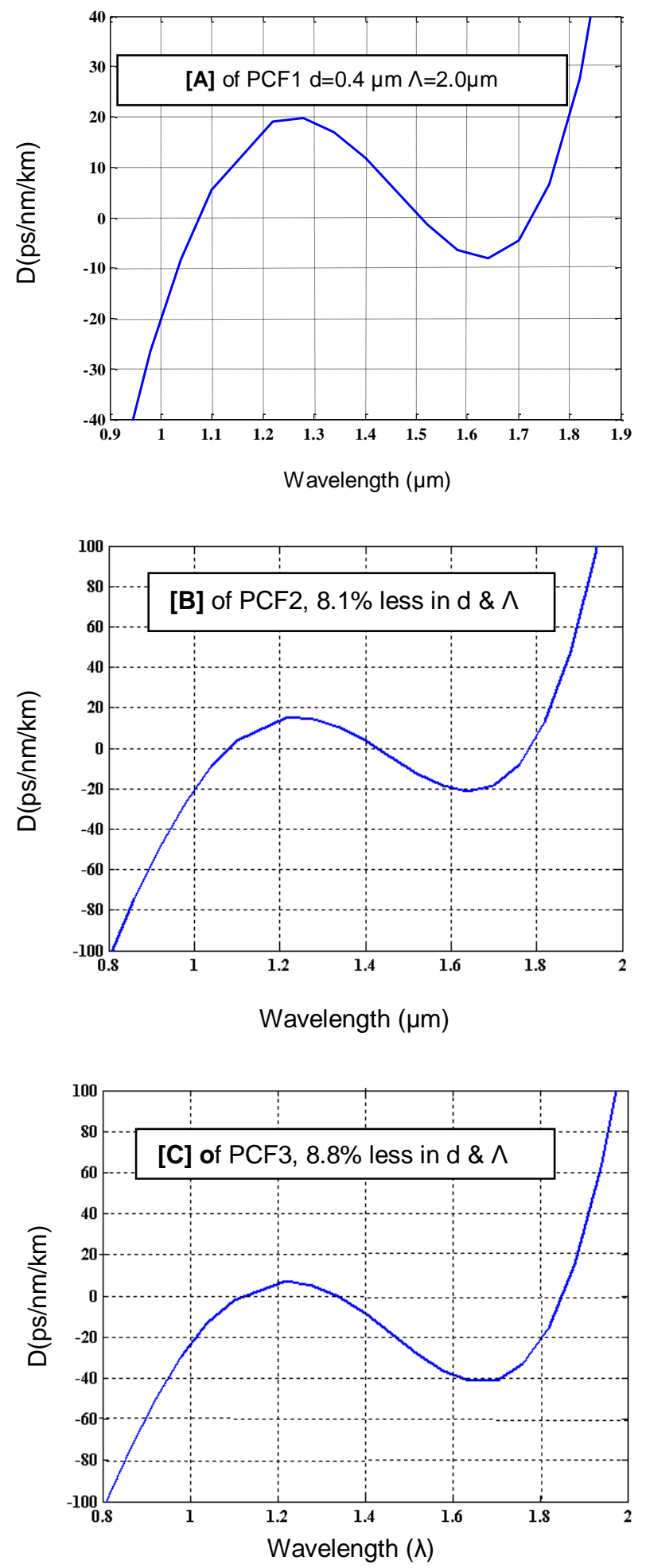

Fig .6. Dispersion profiles of proposed structures showing triple $\lambda_{\mathrm{ZD}}$ 
Table (1): The parameters of triple zero dispersion wavelength photonic crystal fiber

\begin{tabular}{|c|c|c|c|}
\hline \multirow[t]{2}{*}{ Parameters } & \multicolumn{3}{|c|}{$\begin{array}{c}\text { Photonic Crystal Fiber with } \\
\text { Triple ZDWs }\end{array}$} \\
\hline & P C F 1 & P C F 2 & P C F 3 \\
\hline ZDW1 $(\mu \mathrm{m})$ & 1.08 & 1.09 & 1.14 \\
\hline ZDW2 $(\mu \mathrm{m})$ & 1.50 & 1.42 & 1.34 \\
\hline ZDW3(nm) & 1.72 & 1.78 & 1.85 \\
\hline $\begin{array}{c}\text { ZDWs Separation } \\
\text { (nm) } \\
\text { ZDW1-ZDW2 } \\
\text { ZDW2-ZDW3 }\end{array}$ & $\begin{array}{l}420 \\
220\end{array}$ & $\begin{array}{l}330 \\
360\end{array}$ & $\begin{array}{l}200 \\
510\end{array}$ \\
\hline $\begin{array}{l}\mathrm{D}(\mathrm{ps} / \mathrm{nm} / \mathrm{km}) \\
@: 0.80 \mu \mathrm{m} \\
1.3 \mu \mathrm{m} \\
1.55 \mu \mathrm{m}\end{array}$ & $\begin{array}{l}-105.47 \\
+017.05 \\
-005.34\end{array}$ & $\begin{array}{l}-104.23 \\
+010.42 \\
-012.29\end{array}$ & $\begin{array}{l}-103.90 \\
-000.47 \\
-028.11\end{array}$ \\
\hline $\begin{array}{l}\mathrm{dD}(\lambda) / \mathrm{d} \lambda \\
\left(\mathrm{ps} / \mathrm{nm}^{2} / \mathrm{km}\right) \\
@: 0.80 \mu \mathrm{m} \\
1.3 \mu \mathrm{m} \\
1.55 \mu \mathrm{m}\end{array}$ & $\begin{array}{l}+0.516 \\
-0.075 \\
-0.086\end{array}$ & $\begin{array}{l}+0.515 \\
-0.100 \\
-0.110\end{array}$ & $\begin{array}{l}+0.496 \\
-0.124 \\
-0.140\end{array}$ \\
\hline $\begin{array}{l}\beta^{3}\left(\mathrm{ps}^{3} / \mathbf{k m}\right) \\
\text { @: ZDW1 } \\
\text { ZDW2 } \\
\text { ZDW3 } \\
\end{array}$ & $\begin{array}{l}+0.089 \\
+0.142 \\
+0.390\end{array}$ & $\begin{array}{l}+0.023 \\
-0.150 \\
+0.850\end{array}$ & $\begin{array}{l}+0.052 \\
-0.860 \\
+0.990\end{array}$ \\
\hline $\begin{array}{l}\beta^{3}\left(\mathrm{ps}^{3} / \mathrm{km}\right) \\
@: 0.80 \mu \mathrm{m} \\
1.3 \mu \mathrm{m} \\
1.55 \mu \mathrm{m}\end{array}$ & $\begin{array}{l}-30.39 \\
+23.58 \\
-02.95\end{array}$ & $\begin{array}{l}-30.06 \\
+14.37 \\
-25.97\end{array}$ & $\begin{array}{l}-29.16 \\
-00.76 \\
-59.29\end{array}$ \\
\hline $\begin{array}{l}\text { Confinement loss } \\
\text { X10 }{ }^{5} \mathrm{~dB} / \mathrm{m} \\
@:: 0.80 \mu \mathrm{m} \\
1.3 \mu \mathrm{m} \\
1.55 \mu \mathrm{m} \\
\end{array}$ & $\begin{array}{l}06.0 \\
12.0 \\
17.0\end{array}$ & $\begin{array}{l}06.8 \\
16.0 \\
24.0\end{array}$ & $\begin{array}{l}10.0 \\
25.0 \\
33.0\end{array}$ \\
\hline
\end{tabular}

\section{Conclusions}

To summarize this paper, we have reported results for controlling the dispersion profile of triple ZDWs PCFs. The results show that the position of the ZDWs are sensitive to the micro tuning of $\boldsymbol{d}$ and $\boldsymbol{\Lambda}$. Our proposed PCFs are significantly simpler (from the design point of view) in comparison to other structures which have multi ZDWs, because these structures contain less number of design parameter. On the other hand triple ZDWs are the wavelengths at which PCFs has its maximum information carrying capacity, and suitable for application as WDM. 


\section{Laser Field Distribution in Photonic Crystal Fiber With Triple Zero Dispersion ...}

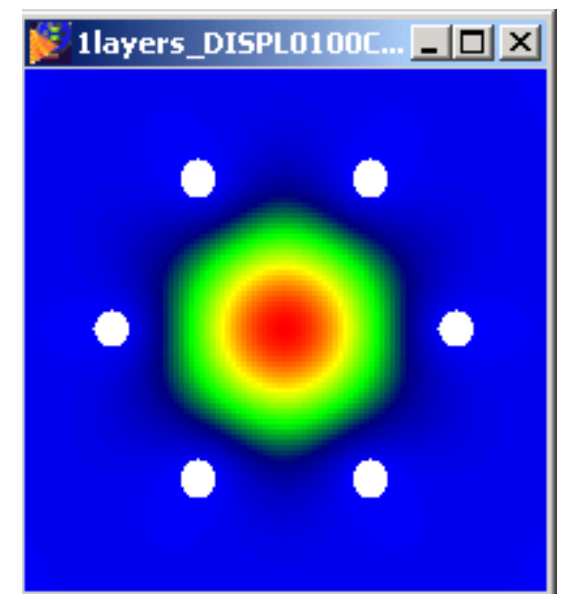

$\Lambda=2.0 \mu \mathrm{m}, \mathrm{d}=0.4 \mu \mathrm{m}$ at $\lambda=0.8 \mu \mathrm{m}$

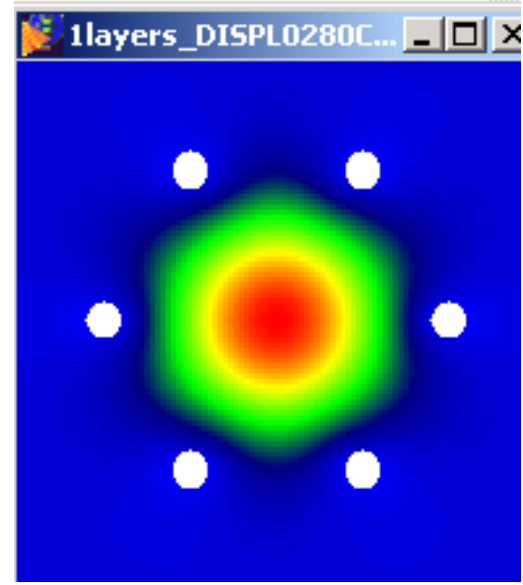

$\Lambda=\Lambda-8.1 \%, d=d-8.1 \%$ at $\lambda=0.8 \mu \mathrm{m}$

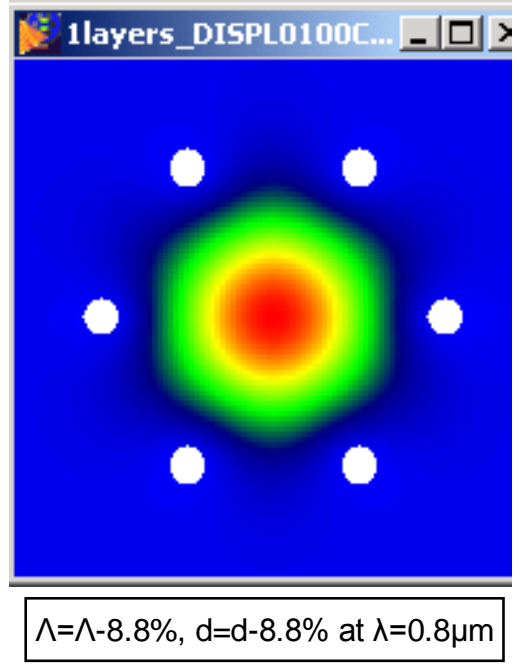

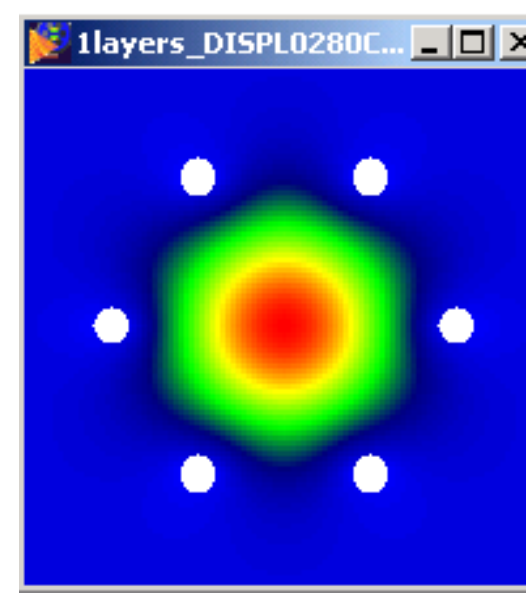

$\Lambda=2.0 \mu \mathrm{m}, \mathrm{d}=0.4 \mu \mathrm{m}$ at $\lambda=1.3 \mu \mathrm{m}$
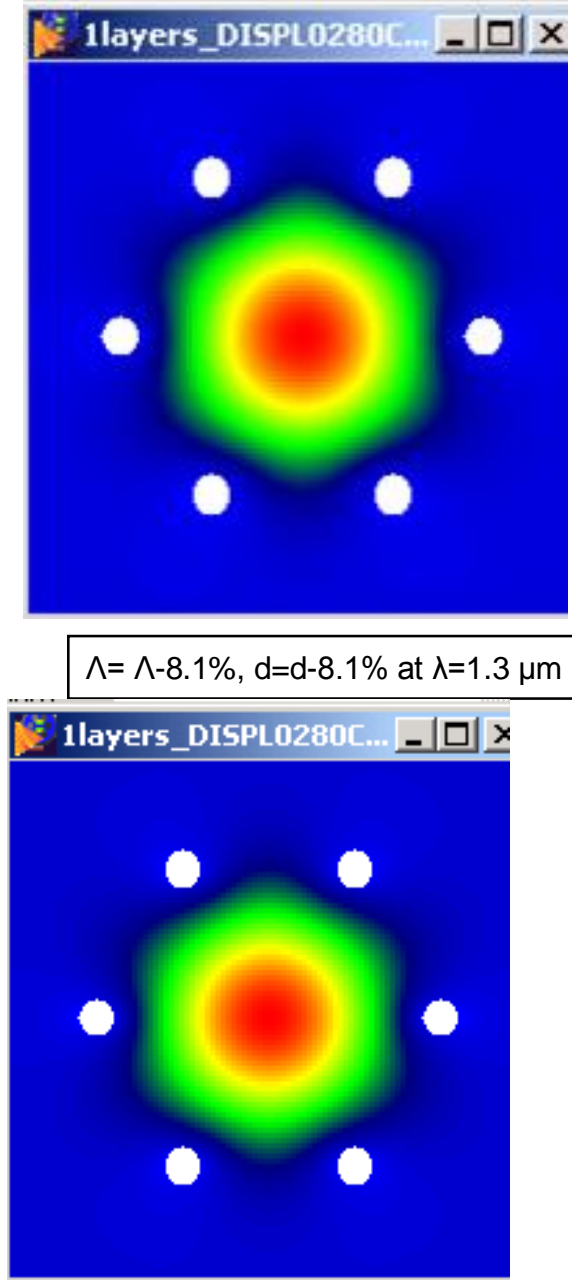

$\Lambda=\wedge-8.8 \%, d=d-8.8 \%$ at $\Lambda=1.3 \mu m$

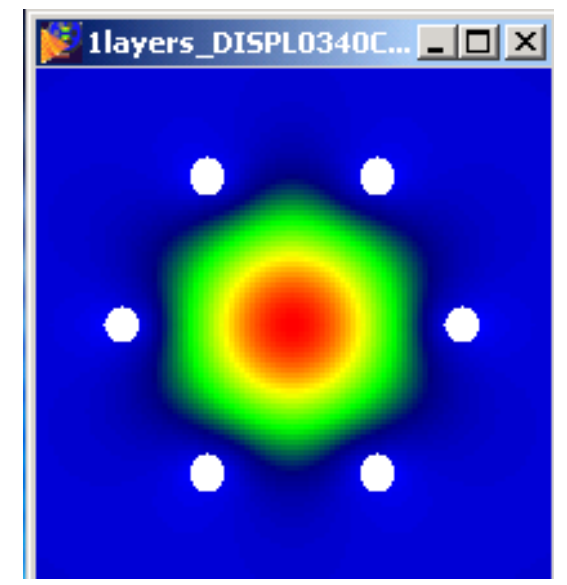

$\Lambda=2.0 \mu \mathrm{m}, \mathrm{d}=0.4 \mu \mathrm{m}$ at $\lambda=1.55 \mu \mathrm{m}$

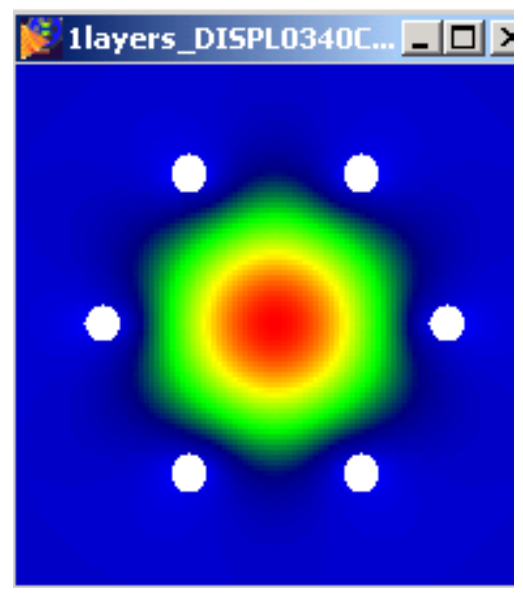

$\Lambda=\Lambda-8.1 \%, \mathrm{~d}=\mathrm{d}-8.1 \%$ at $\Lambda=1.55 \mu \mathrm{m}$

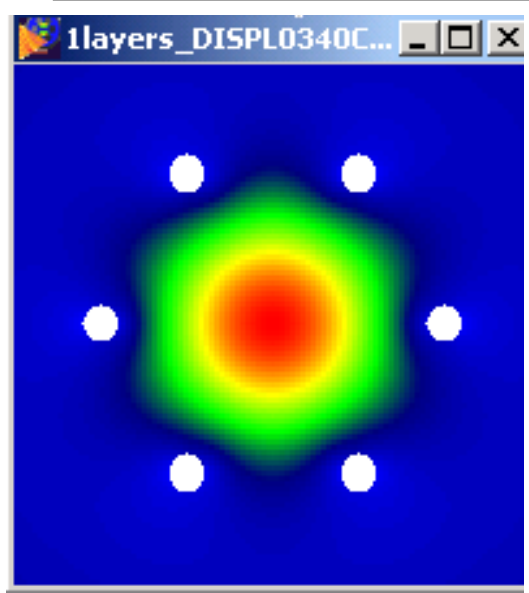

$\Lambda=\wedge-8.8 \%, d=d-8.8 \%$ at $\lambda=1.55 \mu \mathrm{m}$

Fig.7 Laser field distribution of the fundamental mode at communication wavelengths $0.8,1.3 \& 1.55 \mu \mathrm{m}$. 


\section{References}

1) Nielsen M., D., Folkenberg J., R., and Mortensen N., A., Electronics Letters, Vol. 39, No. 25 pp: (1802-1803) 2003.

2) Humbert G., Knight J., C., Bouwmans G., Russel P., St., J., Williams D., P., Roberts P., J., and Mangan B., J., Opt. Exp. Vol. 12, No 8, pp: (1477-1484) 2004.

3) Saitoh K., Florous N., and Koshiba M., Opt. Exp., 13, pp: (8365-8371) 2005.

4) Wadsworth W. J., Knight J. C., Arriaga J., Ortigosa A., Mangan B. J., and Russell P. St. J., Postdeadline paper PD1.5, CLEO"99

5) Ghosh D., Pal M., Roy S., Pal A., Bahadra S.K., McCarthy J., Booky H., , and Kar A., International conference on Fiber Optics and Photonics, Photonics pp: 265-265, 2008.

6) Kudlinski A., Cumberland B. A., Travers J. C., Bouwmans G., Quiquempois Y. and Mussot A. Femtosecond optics group, Imperical College London, London, SW7 2AZ, United Kingdom.

7) Gowre S. C., Sahu P.K., Mahapatra S., and Biswas J. C., International conference on Fiber Optics and Photonics, Photonics, pp:(28-28) 2008.

8) Agrawal A., Kejalakshmy N., Chen J., Lu H., Rahman B. M. A. and Grattan K. T. V., International conference on Fiber Optics and Photonics, Photonics, pp :(218-218) 2008.

9) Varshney S. K and Sinha R. K., J. Micro. And Opto., 2: pp:(32-42) 2002.

10) Knight J.C., and Russell P. St. J., Science, 296: pp:(267-277) 2002.

11) Kuhlmey B. T., White T. P., Renversez G., Maystre D., Botten L. C., Sterek C. M. and McPhedran R. C., J. Opt. Soc. Am. B.19:(2331- 2340) 2002.

12) Ferrrando A., Silvestre E., Miret J. J., and Andres P., Opt. Lett.,25pp:(790- 792) 2000.

13) Saito K., Fujisawa T., Kirihara T., and Koshiba M., Opt. Express, Vol. 14, pp:(6572-6583) 2006.

14) Poli F., Cucinotta A., and Selleri S., "Photonic crystal fiber properteas and applications" Springer, 2007. 
15) CUDOS MOF UTILITIES Software CCommonwealth of Australia 2004. http://www.physics.usyd.edu.au/cudos/mofsoftware/.

16) Kuhlmey B. T., McPhedran R.C., Sterek C. M., Robinson P.A., Renversez G, and Maystre D., Opt. Exp. 10 pp: (1285-1290) 2002.

17) Saitoh K. and Koshiba M., J. Lightwave Technology Vol.23, No.11, pp: (3580-3590) 2005.

18) Einarsson G., "Principles of lightwave communications", 1996. John Wiley and Sons Ltd. England.

19) Basch E. E. B, 'Optical Fiber Transmission", 1986, Howard W. Sams \&Co. USA.

20) Buck J. A., "Fundamentals of optical fibers" 2004, $\mathbf{2}^{\text {nd }}$ Edition, A John Wiley \& Sons. Inc. Hoboken, New Jers

21) Wong K. L. G., "Nonlinear optic in photonic crystal fibers", M.Sc. Thesis, University of Auckland, 2003.

22) Saitoh K., Koshiba M., and Mortensen N. A., J. Phys. 8: pp:(1-9) 2006.

23) Guobin R., Zhi W., Shugin L., and Shuisheng J., Opt. Exp. Vol. 11, No 11, pp:(1310- 1321) 2003. 